\title{
Decomposing Drivers of Rising Household Carbon Emission in the Philippines
}

\author{
Moises Neil V. Seriño ${ }^{1,2}$ \\ ${ }^{1}$ Chair of Development Economics, Göttingen University, Germany \\ ${ }^{2}$ Department of Economics, Visayas State University, Philippines \\ *Corresponding Author: mserino@uni-goettingen.de
}

Copyright (C 2014 Horizon Research Publishing All rights reserved.

\begin{abstract}
This study investigates the major factors affecting the increase in household carbon emission in the Philippines using the well known analytical tool - Kaya identity. The changes in Kaya factors of household emission were analyzed using the logarithmic mean Divisia index. Results show that a positive relationship between emission and income is evident when disaggregating household carbon emission across income quintiles. The increase in carbon emission at the poorest quintile is largely driven by the increase in income while at the richest quintile it is explained more by the increase in energy expenditure relative to income. Overall, the increase in household carbon emission across income quintiles is offset by the decrease in "carbon intensity" of household consumption. If policy makers are keen in stabilizing household carbon emission, they should device policies that aim to improve household energy efficiency.
\end{abstract}

Keywords Carbon Emission, Kaya Identity, Philippine Households, Energy Expenditure

\section{Introduction}

Reducing anthropogenic green house gas emission is seen as the most important and direct action in mitigating climate change. Cutting down emission may seem to be a straight forward approach, but implementing it is an enormous challenge since reducing emission will directly harm the economy. Rich countries fear the economic disruption that may accompany the reduction of emissions while poor countries argue that their economic progress should not be hampered by limiting of emissions and that the current level of emission is not of their doing [1], [2]. This paper, however, will not focus on determining who emits most but rather this will examine the driving factors behind the surging increase of carbon emission 1. According to Duro and Padilla [2] many factors influence the level of emission namely:

1 In our analysis, we focus only on carbon dioxide $\left(\mathrm{CO}_{2}\right)$ emission because it is the primary green house gas emitted through human activities [3]. economic and demographic developments, technological change, resource endowments, institutional framework, lifestyle and international trade. Evaluating these factors is of particular interest to researchers and policy makers in projecting future emission path and mitigating climate change. Among these factors mentioned by Duro and Padilla [2], this paper attempts to focus on the lifestyle of people as reflected by their consumption behavior.

Literature is abundant with studies analyzing the factors influencing carbon emission on a national or regional level [4]-[7]. Xu and Ang [8] provided a comprehensive review of studies investigating the driving factors influencing carbon emission. They reviewed 80 papers using index decomposition applied to $\mathrm{CO}_{2}$ emission studies. Carbon emission is well studied and documented in literature be it in global, regional or household level particularly in developed countries. However, studies focusing in household level especially from developing countries are very limited. Hence, we fill this gap by analyzing the driving factors of rising household carbon emission in the Philippines using the well known Kaya identity. Based on this identity, the per capita carbon emission can be disaggregated into three major driving forces namely: carbon intensity, energy intensity and affluence. This is another novelty in our study because Kaya identity is commonly applied at a country level analysis. We will show in this paper that it can be applied on a household level analysis.

Households contribute to rising carbon emission by consuming various goods and services. In the United States, more than $80 \%$ of the energy used and $\mathrm{CO}_{2}$ emitted are a consequence of consumer demands and the related economic activities to support these demands [9]. In the United Kingdom, households contribute around $74 \%$ to total emission [10]. While less attention has been given in literature for households from developing countries, their aggregate emission is rising [11]. Hence, it is of great policy relevance to investigate household emission associated with consumption for the projection of a future consumption path. In this vein, we want to shed some light on the issue of what factors influence rising carbon emission from a developing country; particularly the Philippines. On aggregate, the 
household carbon emission in the Philippines may still not be at an alarming level compared to those in developed countries but it is steadily rising. Because of this, we find it relevant to investigate the factors affecting household carbon emission and evaluate whether there is a potential for households to be leading a less carbon intensive lifestyle and not following the consumption trajectory of households from developed countries. In addition, results of the study will help policy makers to device policies that can help regulate household carbon emissions.

\section{Methodology}

To address the objectives of this study, we proceed in two major steps. First, we decompose household carbon emission into Kaya factors. Second, we use the log mean Divisia index to investigate the factors affecting the change in household carbon emission from year 2000 to 2006 .

\subsection{Kaya Factors of Household Carbon Emission}

We use the Kaya identity in disaggregating the major driving forces affecting household carbon emission. Kaya identity states that the total carbon emission can be expressed as a product of four basic inputs: carbon intensity per energy consumed, energy intensity per unit GDP, GDP per capita and population. Kaya identity as an analytical tool has been frequently used to explore the major driving forces of global emission [12]. This expression is similar to IPAT identity where the environmental impact of emission (I) can be expressed as a product of population (P) affluence (A) and technology (T) [12],[13] . Thus, total carbon emission can be expressed as:

$$
\mathrm{CO}_{2 \mathrm{i}}=\left(\mathrm{CO}_{2 \mathrm{i}} / \mathrm{E}_{\mathrm{i}}\right) *\left(\mathrm{E}_{\mathrm{i}} / \mathrm{GDP}_{\mathrm{i}}\right) *\left(\mathrm{GDP}_{\mathrm{i}} / \mathrm{P}_{\mathrm{i}}\right) *\left(\mathrm{P}_{\mathrm{i}}\right)
$$

where $\mathrm{CO}_{2 i} / E_{i}$ reflects the carbon emission per unit of energy consumed. This can also be called carbon intensity or carbonization index. $E_{i} G D P_{i}$ means the energy intensity or the amount of energy consumed per unit GDP and $G D P_{i} / P_{i}$ is the income per capita. This identity might also be used to analyze per capita emissions, that is,

$$
\mathrm{CO}_{2 \mathrm{i}} / \mathrm{P}_{\mathrm{i}}=\left(\mathrm{CO}_{2 \mathrm{i}} / \mathrm{E}_{\mathrm{i}}\right) *\left(\mathrm{E}_{\mathrm{i}} / \mathrm{GDP}_{\mathrm{i}}\right) *\left(\mathrm{GDP}_{\mathrm{i}} / \mathrm{P}_{\mathrm{i}}\right)
$$

Grounded on this concept, we apply Kaya identity decomposition analysis on a household level. So, total household carbon footprint can be expressed as follows

$$
\mathrm{CO}_{2 \mathrm{hh}}=\left(\mathrm{CO}_{2 \mathrm{hh}} / \mathrm{E}_{\mathrm{hh}}\right) *\left(\mathrm{E}_{\mathrm{hh}} / \mathrm{Inc}_{\mathrm{hh}}\right) *\left(\mathrm{Inc}_{\mathrm{hh}} / \mathrm{Mem}_{\mathrm{hh}}\right) *\left(\mathrm{Mem}_{\mathrm{hh}}\right)
$$

where $\mathrm{CO}_{2 h h}$ is the total carbon emission of a given household and $\mathrm{CO}_{2 h h} / E_{h h}$ captures the amount of carbon emitted per energy consumption of households or simple "carbon intensity". Household energy will be computed from the households' consumption of fuel, light and transportation. These are the expenditure items related to households' direct energy consumption $2 . E_{h h} / I n c_{h h}$ reflects the ratio of

2 Although other household consumption items also consume energy household energy expenditure to total household income or this could be termed as simple "energy intensity". $I n c_{h h} / \mathrm{Mem}_{h h}$ is the household income divided among household members $\left(\mathrm{Mem}_{h h}\right)$ or the income per capita. Similarly, the Kaya decomposition can also be used to analyze carbon emission per capita:

$$
\mathrm{CO}_{2 \mathrm{hh}} / \mathrm{Mem}_{\mathrm{hh}}=\left(\mathrm{CO}_{2 \mathrm{hh}} / \mathrm{E}_{\mathrm{hh}}\right) *\left(\mathrm{E}_{\mathrm{hh}} / \mathrm{Inc}_{\mathrm{hh}}\right) *\left(\mathrm{Inc}_{\mathrm{hh}} / \mathrm{Mem}_{\mathrm{hh}}\right)
$$

Alternatively, we can represent equation (4) by

$$
\text { emit }=\mathrm{CO}_{2} \mathrm{e} * \mathrm{En} * \mathrm{Inc}
$$

where emit captures emission per capita, $\mathrm{CO}_{2} e$ is the carbon emission per energy consumed measured in terms of tons of $\mathrm{CO}_{2}$ per peso (Php) spent on energy, En represents the ratio of energy expenditure to income and Inc is the income per capita.

\subsection{Decomposing change in per capita emission}

To analyze the change in per capita emission from 2000 to 2006 as influenced by household Kaya factors, we apply the decomposition method of logarithmic mean Divisia index (LDMI). There are two approaches, the multiplicative and additive approach. For this study, we apply the additive approach to investigate the difference of household carbon emission from 2000 to 2006. Ang [14] provides a detailed approach in using LDMI approach to decomposition analysis. We follow his method and we express the change in household carbon emission as

$$
\Delta \text { Emit }=\mathrm{Emit}^{06}-\mathrm{Emit}^{00}=\Delta \mathrm{CO}_{2} \mathrm{e}+\Delta \mathrm{En}+\Delta \mathrm{Inc}
$$

where

$$
\begin{aligned}
& \Delta \mathrm{CO}_{2} e=\sum i\left(\frac{\text { Emit }_{i}^{06}-\text { Emit }_{i}^{00}}{\operatorname{lnEmit}_{i}^{06}-\ln E m i t_{i}^{00}}\right) * \ln \left(\frac{\mathrm{CO}_{2} e^{06}}{\mathrm{CO}_{2} e^{00}}\right) \\
& \Delta E n=\quad \Sigma i\left(\frac{E m i t_{i}^{06}-E^{06} i_{i}^{00}}{\operatorname{lnEmit}_{i}^{06}-\ln E m i t_{i}^{00}}\right) * \ln \left(\frac{E n^{06}}{E n^{00}}\right) \\
& \Delta I n c=\quad \operatorname{Li}\left(\frac{\text { Emit }_{i}{ }^{06}-\text { Emit }_{i}{ }^{00}}{\operatorname{lnEmit}_{i}^{06}-\ln E m i t_{i}^{00}}\right) * \ln \left(\frac{\operatorname{Inc}{ }^{06}}{\operatorname{Inc} c^{00}}\right)
\end{aligned}
$$

where $\operatorname{lnEmit}_{i}{ }^{y r}$ is the log of household emission in a given year.

\subsection{Data}

Currently there is no representative dataset on household carbon emission in the Philippines. Hence, we estimate it by extracting the embodied carbon emission from household consumption. Household carbon emission can be computed as the sum of direct and indirect emission. Take for example, when a household decides to buy a computer, the associated emission from the computer comes directly from its production and indirectly in the production of inputs such as metals and plastics. To account for the embodied carbon emission from household consumption, we matched the

embodied in the production but these are considered indirect energy consumption. Hence for energy expenditure per income, for this analysis we only capture the direct energy consumption of the households. 
sectors from input-output table and consumption categories from household expenditure survey for the years 2000 and 2006. The estimation of carbon emission based on combining the input-output table and the household expenditure can be contested in several ways 3 . However due to lack of other good alternatives, many studies still rely on the methods of input-output analysis in estimating household carbon emission [9], [10], [15], [16], [17], [18].

To do this, we combine (i) the Philippine input-output (IO) table for 2000, (ii) the carbon emission intensity for different goods from the Global Trade Analysis Project (GTAP) and (iii) the household expenditure survey from Family Income and Expenditure Survey (FIES). We extract carbon intensity of economic sectors by combining IO table with GTAP's carbon emission coefficient4. Then, we match the sectors with the items listed in the household expenditure. The IO table is a $274 \times 274$ matrix while the GTAP coefficient is a $58 \times 58$ matrix. To resolve the differences in matrices, we mapped out the GTAP sectors with the IO table using the concordances provided by GTAP. Correspondingly, the carbon intensities of economic sectors can be estimated as follows

$$
\mathrm{CI}_{\mathrm{i}}=\mathrm{c}^{\prime}(\mathrm{I}-\mathrm{A})^{-1} \mathrm{y}
$$

where $C I_{j}$ is the carbon intensity of each economic sector in the input-output table and $c$ is a vector of carbon coefficients taken from the Global Trade Analysis Project (GTAP) [20]. $A$ is the technical coefficients, $(I-A)^{-1}$ is known as the Leontief inverse and $y$ is the vector of final demand for commodities. Then, we match these carbon intensities with the consumption categories $\left(\operatorname{Exp}_{i}\right)$ listed in the household expenditure survey. Summing up all the individual emission from individual expenditure, we derived our estimated household carbon emission $\left(\mathrm{CO}_{2 h h}\right)$.

$$
C O_{2 h h}=\Sigma C I_{i}^{*} \operatorname{Exp}_{j}
$$

Based on our analysis, the estimated carbon emissions of Philippine households in 2000 were on the average around 1.5 tons of $\mathrm{CO}_{2}$ per household and this amount increased to 1.9 tons of $\mathrm{CO}_{2}$ per household in 2006. To investigate what drives the increase in household carbon emission, we employ Kaya identity decomposition analysis.

\section{Results and Discussion}

We decompose carbon emission per capita into three main factors, namely: (i) income effect, (ii) simple "carbon intensity" effect, and (iii) simple "energy intensity" effect. The income effect captures the changes in income per capita, the simple "carbon intensity" is define as the carbon emission per peso (Php) 5 spent in the energy consumption and the simple "energy intensity" captures the ratio of total energy expenditure to total income.

Table 1 presents the Kaya factors across household characteristics. Urban households have higher carbon emission per capita in both years as compared to rural households. The emission per capita as well as the income per capita of urban households is twice that of in rural households. Also the ratio of carbon emission to energy expenditure and the ratio of energy expenditure to income are slightly higher in urban households than in rural households. This is because urban households have better access to electricity and are more likely to use cars for transportation. Public transport in urban areas is more frequent and readily available as compared to rural areas. In addition, a lot of households in the rural areas are also out of the energy system.

We observe that younger households, aging below 45 years old, have lower carbon emission per capita than older households. The carbon emission per energy expenditure and the ratio of energy to income is relatively similar across age of household head. Education appears to be positively related to carbon emission and income per capita. The higher the educational attainment of household head the higher the carbon emission and income per capita. Household heads with at least a college education have carbon emission and income higher than the rest. Table 1 also shows that the other Kaya factors: carbon emission per energy expenditure and energy expenditure per income, increase as households obtain higher education.

Figure 1 shows the component of Kaya identity for both years disaggregated in income quintiles. The level of carbon emission and income per capita are higher in 2006 than in 2000. Households in the $5^{\text {th }}$ quintile have relatively higher level of carbon emission and income per capita in both years as compared to the rest of the households. The carbon emission per capita mirrors the behavior of income per capita implying a strong correlation between carbon emission and income. 
Table 1. Kaya factors and household characteristics.

\begin{tabular}{|c|c|c|c|c|c|c|c|c|}
\hline \multirow[t]{2}{*}{ HH Characteristics } & \multicolumn{2}{|c|}{$\begin{array}{c}\mathrm{CO}_{2} \text { emission } \\
\text { per capita }\left(\mathrm{tCO}_{2}\right)\end{array}$} & \multicolumn{2}{|c|}{$\begin{array}{c}\text { Income } \\
\text { per capita (Php) }\end{array}$} & \multicolumn{2}{|c|}{$\begin{array}{c}\mathrm{CO}_{2} \text { emission / } \\
\text { Energy }\left(\mathrm{tCO}_{2} / \mathrm{Php}\right)\end{array}$} & \multicolumn{2}{|c|}{$\begin{array}{c}\text { Energy / } \\
\text { Income (\%) }\end{array}$} \\
\hline & 2000 & 2006 & 2000 & 2006 & 2000 & 2006 & 2000 & 2006 \\
\hline \multicolumn{9}{|l|}{ Location } \\
\hline Rural & 0.17 & 0.25 & $18,370.79$ & $25,092.93$ & 0.00012 & 0.00012 & 0.08 & 0.09 \\
\hline Urban & 0.42 & 0.67 & $40,081.97$ & $55,588.90$ & 0.00015 & 0.00014 & 0.09 & 0.10 \\
\hline \multicolumn{9}{|l|}{ Age } \\
\hline less than 30 & 0.30 & 0.43 & $28,845.19$ & $38,118.08$ & 0.00014 & 0.00013 & 0.08 & 0.09 \\
\hline 30 to 45 & 0.29 & 0.38 & $27,542.76$ & $33,495.82$ & 0.00014 & 0.00013 & 0.09 & 0.10 \\
\hline 45 to 60 & 0.34 & 0.47 & $34,358.47$ & $42,301.97$ & 0.00013 & 0.00012 & 0.09 & 0.10 \\
\hline above 60 & 0.34 & 0.49 & $33,795.01$ & $43,360.02$ & 0.00013 & 0.00013 & 0.09 & 0.10 \\
\hline \multicolumn{9}{|l|}{ Education } \\
\hline No formal education & 0.13 & 0.16 & $14,978.50$ & $17,685.38$ & 0.00011 & 0.00011 & 0.08 & 0.09 \\
\hline Elementary & 0.19 & 0.24 & $18,688.73$ & $22,791.57$ & 0.00013 & 0.00012 & 0.08 & 0.09 \\
\hline High School & 0.30 & 0.42 & $27,286.03$ & $35,107.96$ & 0.00014 & 0.00013 & 0.09 & 0.10 \\
\hline College & 0.62 & 0.89 & $62,558.96$ & $79,008.04$ & 0.00014 & 0.00013 & 0.09 & 0.10 \\
\hline Average & 0.32 & 0.44 & $31,206.86$ & $38,776.22$ & 0.00014 & 0.00013 & 0.09 & 0.10 \\
\hline
\end{tabular}

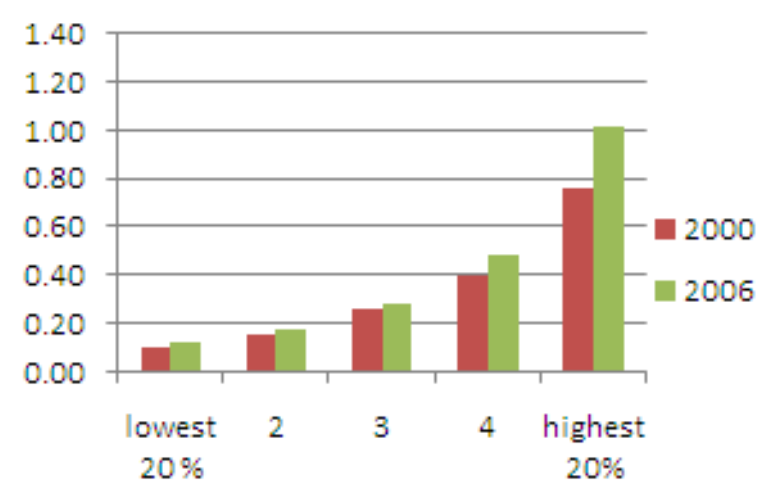

a. $\mathrm{CO}_{2}$ emission per capita $\left(\mathrm{tCO}_{2}\right)$

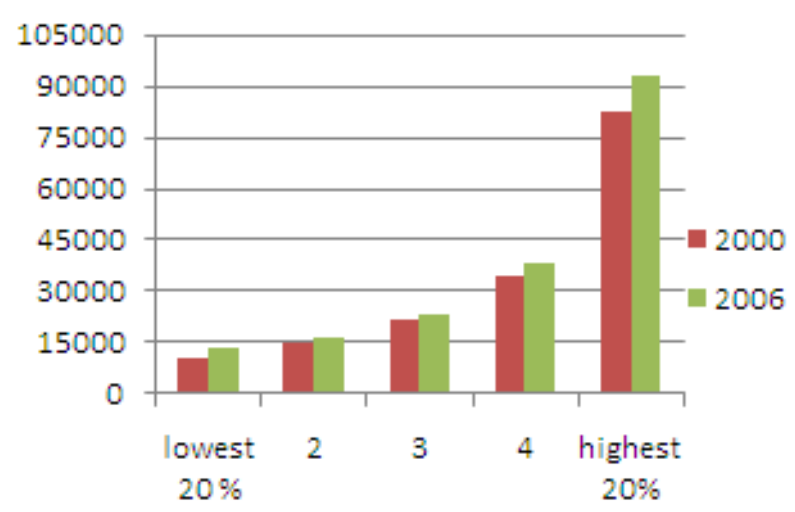

b. Income per capita (Php)

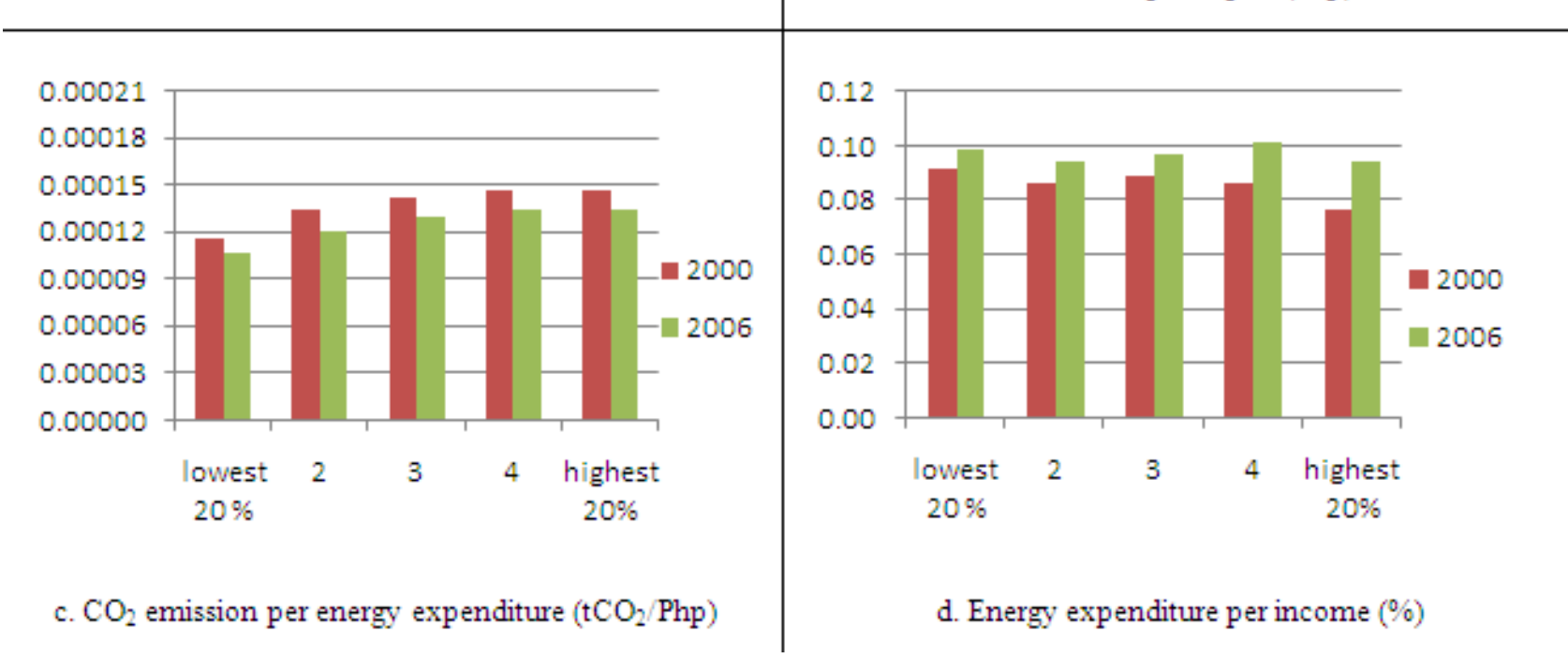

Figure 1. Decomposition of carbon emission per capita by Kaya factors. 
There are many factors that influence households' carbon emission. With Kaya decomposition, we highlight two key factors affecting household emission, these are simple "carbon intensity" and simple "energy intensity". We used household total energy expenditure as a proxy to the quantity of energy goods consumed by households in computing these simple "intensities".

"Carbon and energy intensity" show contrasting patterns with each other across income quintiles. "Carbon intensity" (the emission per energy expenditure) depicted an increasing trend across income quintiles while "energy intensity" (the ratio of energy expenditure to income) appear to be declining as households' income increase (Figure 1c \& 1d). On the average, households on the lowest quintile (poor households) have lower carbon emission per energy expenditure than households in the highest quintile (rich households) 6 . However, "carbon intensity" declines across quintiles over time. The level of "carbon intensity" in 2006 is lower than what was observed in 2000 and the pattern is consistent across income quintiles. The decline in "carbon intensity" across household quintiles can be explained by the shift in energy fuel to a less carbon intensive fuels. According to US Energy Information Administration [21], a decline in carbon intensity can indicate a shift away from fossil fuels and a shift towards a less carbon intensive fuels.

Across income quintiles, the ratio of energy expenditure to income does not fluctuate significantly but it seems to be declining as households' income increase. Poor households, on average have a higher ratio on energy expenditure to income than the rich households. Graphically, the difference is not that significant. Though there is a huge disparity in income across households, the ratio of energy expenditure to income is relatively similar across households. Overall, there is an increase in "energy intensity" from its level in 2000 to 2006 and this observation is consistent across income quintile. Energy intensity is an indication of energy efficiency. This result implies that household consumption in the Philippines does not show evidence of improved energy efficiency.

For policy makers, it is relevant to examine how carbon emission changes over time. We use the method of LMDI to investigate the underlying changes in household carbon emission. Figure 2 shows the change in household carbon emission disaggregated into Kaya factors across income quintiles. Results show that the increase in emission in the poorest households is largely driven by income effect. On the other hand, the increase in carbon emission in the richest household quintile is attributed mainly to the change in simple "energy intensity" rather than in income effect. As households become affluent, the share of income effect to the change in carbon emission declines but the share of energy expenditure to income increases. This implies that as households' income increase, they consume more energy

6 We ranked the households base on their total income and divide them equally into quintiles. The lowest quintile captures the lowest $20 \%$ of the households in terms of income while the highest quintile represents the highest $20 \%$. For simplicity, we refer the lowest quintile as the poor households and the highest quintile as the rich households. intensive goods. Though the influence of income cannot be disregarded in explaining the change in household emission, it is the ratio of energy expenditure to income that explains more what drives carbon emission as households get richer.

Based on our analysis, rich households are leading energy intensive lifestyles. This is reflected in their expenditure on energy intensive goods such as fuel, light and transportation. However, the increase in emission is offset by a declining rate of "carbon intensity". Across income quintiles, there is a uniform decrease in "carbon intensity". This might be due to an increase in renewable energy production in the Philippines [22], [23]. This decline in simple "carbon intensity" also mirrors the global scenario where a majority of the cases reviewed by Xu and Ang [8] reported a decrease in the aggregate carbon intensity in the residential sector. Steckel et al. [24] also showed in their extended Kaya decomposition analysis that the World and OECD countries posted a decline in both energy intensity and carbon intensity.

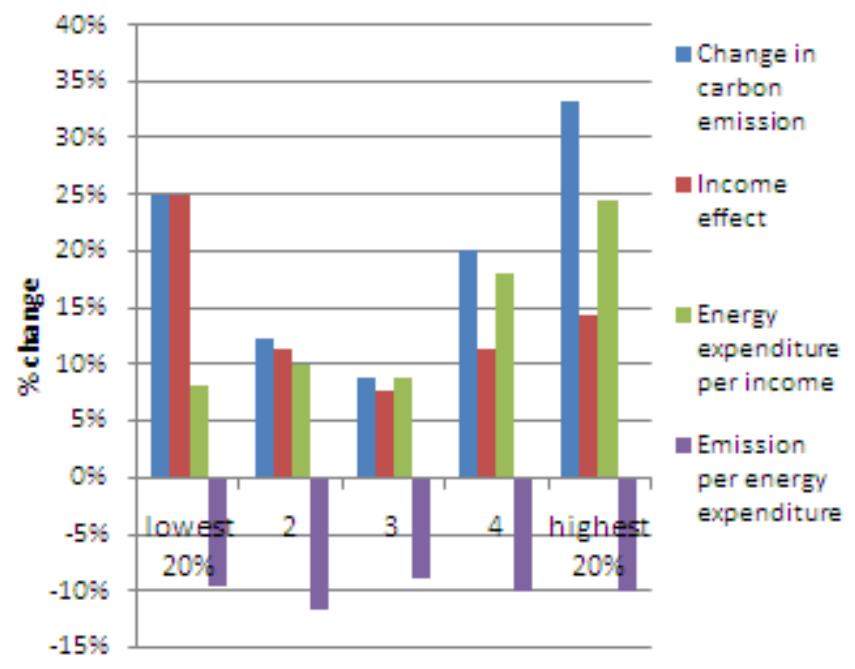

Figure2. Percentage change of Kaya factors from 2000 to 2006.

On a global scenario, US Energy Information Administration [21] reports an overall decline in energy intensity both in non-OECD and OECD countries. Similarly, Steckel et al. [24] showed that in China the impact of economic growth on emissions was compensated for by the decline in energy intensity using the Kaya decomposition method. This only means that one of the plausible ways to reduce household carbon emission in the Philippines is by curtailing the level of household energy intensity.

To curb down household emission, policy makers should set their focus on the rising share of energy expenditure to income. Policies related to this likely involve improving energy efficiency. This can be done by producing a similar level of output at a lower level of energy requirement, or using a cleaner source of energy such as renewable energy sources. Another option is to shift production to a lesser energy intensive production scheme. Goods which are produced efficiently should be made available to households so that they will have option for green consumption. On the 
household side, this means spending less on energy intensive goods yet maintaining the same standard of living.

\section{Conclusion}

We applied the well known analytical tool, Kaya identity, in investigating major factors that affects the rising household carbon emission in the Philippines. According to Kaya identity, carbon emission per capita can be expressed as a product of namely: (i) carbon intensity, (ii) energy intensity and (iii) affluence or income per capita. Likewise on a household level, the emission per capita can be disaggregated into (i) simple "carbon intensity" (the emission per household energy expenditure), (ii) simple "energy intensity" (the ratio of household energy expenditure to total income) and (iii) income per capita. Our analysis shows that emission per capita and income per capita behave similarly. Both increase as households' income increase. This reflects a strong positive correlation between carbon emission and income. The simple "carbon intensity" also increases as households' income increase while the simple "energy intensity" or the ratio of energy expenditure to income seems to be declining.

To analyze the underlying changes in per capita emission, we use the logarithmic mean Divisia index to disaggregate household carbon emission. At the lowest quintile, the change in carbon emission is explained largely by the increase in income while at the highest quintile the change in per capita emission is mainly driven by the simple "energy intensity" effect or the ratio of energy expenditure to income. For poor households (or households in the lowest income quintile), an increase in income translates to increase in emission while for rich households (or households in the highest income quintile) an increase income explains only a portion of the total change in household emission but it is the ratio of energy expenditure to income that largely affects the level of emission. Households in the highest income quintile have the capacity to consume energy intensive goods related to transportation, electricity and other luxury items translating to higher energy usage. But the increase in carbon emission per capita is compensated by the decline in simple "carbon intensity" across income quintile. This shows that the level of emission per energy expenditure decreases over time.

If policy makers are keen in reducing household carbon emission, they should focus their efforts in curbing down "energy intensity" or the ratio of energy expenditure to income. This entails improvement of energy efficiency in either production or consumption.

\section{Acknowledgements}

The author is very grateful for the helpful suggestions and comments of the two anonymous referees, to EXPERTS 1 - Erasmus Mundus Partnership in South and
South-East Asia for the financial support to carry out this research, to Entdeken project and to the supervision of Prof Stephan Klasen. All remaining errors are mine.

\section{REFERENCES}

[1] M. T. Heil and Q. T. Wodon, "Inequality in CO2 Emissions Between Poor and Rich Countries," The Journal of Environment Development, vol. 6, no. 4, pp. 426-452, Dec. 1997.

[2] J. A. Duro and E. Padilla, "International inequalities in per capita CO2 emissions: A decomposition methodology by Kaya factors," Energy Economics, vol. 28, no. 2, pp. 170-187, Mar. 2006.

[3] C. C. D. US EPA, "Carbon Dioxide Emissions," 2013. [Online]. Available:http://www.epa.gov/climatechange/ghge missions/gases/co2.html. [Accessed: 01-Aug-2013].

[4] J. W. Sun, "Decomposition of aggregate CO2 emissions in the OECD: 1960-1995," Energy Journal, vol. 20, pp. 147-155, 1999.

[5] W. Lise, "Decomposition of CO2 emissions over 1980-2003 in Turkey," Energy Policy, vol. 34, no. 14, pp. 1841-1852, Sep. 2006.

[6] S. C. Bhattacharyya and W. Matsumura, "Changes in the GHG emission intensity in EU-15: Lessons from a decomposition analysis," Energy, vol. 35, no. 8, pp. 3315-3322, Aug. 2010.

[7] F. Vinuya, F. DiFurio, and E. Sandoval, "A decomposition analysis of $\mathrm{CO} 2$ emissions in the United States," Applied Economics Letters, vol. 17, no. 10, pp. 925-931, 2010.

[8] X. Y. Xu and B. W. Ang, "Index decomposition analysis applied to CO2 emission studies," Ecological Economics, vol. 93, pp. 313-329, Sep. 2013.

[9] S. Bin and H. Dowlatabadi, "Consumer lifestyle approach to US energy use and the related CO2 emissions," Energy Policy, vol. 33, no. 2, pp. 197-208, Jan. 2005.

[10] G. Baiocchi, J. Minx, and K. Hubacek, "The Impact of Social Factors and Consumer Behavior on Carbon Dioxide Emissions in the United Kingdom," Journal of Industrial Ecology, vol. 14, no. 1, pp. 50-72, 2010.

[11] World Bank, "CO2 emissions (metric tons per capita) | Data | Table," 2013. [Online]. Available: http://data.worldbank.org/indicator/EN.ATM.CO2E.PC/coun tries?display $=$ default. [Accessed: 28-Sep-2013].

[12] IPCC, "Emissions Scenarios," 2013. [Online]. Available: http://www.ipcc.ch/ipccreports/sres/emission/index.php?idp $=50$. [Accessed: 31-Jul-2013].

[13] E. A. Rosa and T. Dietz, "Human drivers of national greenhouse-gas emissions," Nature Climate Change, vol. 2, no. 8, pp. 581-586, Jun. 2012.

[14] B. . Ang, "Decomposition analysis for policymaking in energy:: which is the preferred method?," Energy Policy, vol. 32, no. 9, pp. 1131-1139, Jun. 2004. 
[15] M. Büchs and S. V. Schnepf, "Who emits most? Associations between socio-economic factors and UK households' home energy, transport, indirect and total $\mathrm{CO} 2$ emissions," Ecological Economics, vol. 90, pp. 114-123, Jun. 2013.

[16] J. Parikh, M. Panda, and N. S. Murthy, "Consumption patterns by income groups and carbon-dioxide implications for India: 1990-2010," International Journal of Global Energy Issues, vol. 9, no. 4-6, 19971997.

[17] M. Lenzen, "Energy and greenhouse gas cost of living for Australia during 1993/94," Energy, vol. 23, no. 6, pp. 497-516, Jun. 1998.

[18] J. Golley and X. Meng, "Income inequality and carbon dioxide emissions: The case of Chinese urban households," Energy Economics, vol. 34, no. 6, pp. 1864-1872, Nov. 2012.

[19] R. Kok, R. M. J. Benders, and H. C. Moll, "Measuring the environmental load of household consumption using some methods based on input-output energy analysis: A comparison of methods and a discussion of results," Energy Policy, vol. 34, no. 17, pp. 2744-2761, Nov. 2006.

[20] H.-L. Lee, “An Emissions Data Base for Integrated
Assessment of Climate Change Policy Using GTAP," Center for Global Trade Analysis, 2008. [Online]. Available: http://www.gtap.agecon.purdue.edu/resources/res_display.as $\mathrm{p}$ ?RecordID $=1143$.

[21] US Energy Information Administration, "International Energy Outlook 2011,” 2011. [Online]. Available: http://www.eia.gov/forecasts/ieo/pdf/0484(2011).pdf. [Accessed: 01-Aug-2013].

[22] Climate Change Commission, "Sustainable Energy," 2013. [Online]. Available: http://climate.gov.ph/index.php/mitigation/sustainable-energ y. [Accessed: 26-Sep-2013].

[23] Department of Energy, "Renewable Energy Tables and Figures," 2013. [Online]. Available:

http://www.doe.gov.ph/renewable-energy-res/renewable-ene rgy-tables-and-figures/284-re-share-in-total-primary-energyconsumption. [Accessed: 27-Sep-2013].

[24] J. C. Steckel, M. Jakob, R. Marschinski, and G. Luderer, "From carbonization to decarbonization?-Past trends and future scenarios for China's CO2 emissions," Energy Policy, vol. 39, no. 6, pp. 3443-3455, Jun. 2011. 